\title{
How can social and environmental services be provided for mobile Tibetan herders? Collaborative examples from Qinghai Province, China
}

\author{
J Marc Foggin ${ }^{1,2^{*}}$ and Marion E Torrance-Foggin ${ }^{1}$
}

\author{
* Correspondence: \\ foggin@plateauperspectives.org \\ 'Plateau Perspectives, 200 Walnut \\ Avenue, St Lambert, Quebec, J4P \\ 2T1, Canada \\ Full list of author information is \\ available at the end of the article
}

\begin{abstract}
Tibetan herders have lived for centuries in the high grasslands of Central Asia, yet many development programs are currently transforming their lives. One of the main assumptions of government policy, in China and around the world, is that the provision of social services is best provided in settled, urban environments. Such drastic changes from traditional pastoral livelihoods, however, may introduce some less-desired outcomes, including high levels of unemployment, loss of hope and cultural loss. Social stability may be affected, and in numerous instances it has been observed that the originally desired benefits (especially the provision of social services such as health care and education) have not been achieved. The case study presented here seeks to demonstrate that social services can be provided to Tibetan herding communities in rural (remote) areas of the Tibetan plateau, at the same time as encouraging and enabling genuine partnerships between local herders and higher-level conservation authorities such as the Sanjiangyuan National Nature Reserve. An analytical approach borrowed from 'participatory action research' and a modified 'balanced scorecard' framework has assisted in project evaluation. With the commitment of key stakeholders, and with sufficient time allowed for trust and understanding to develop, it is possible for various forms and styles of partnerships (collaborative management) to be developed, such that both national conservation goals as well as local development goals may be achieved simultaneously. Further trials of such a collaborative approach should be encouraged, leading to expanded application throughout the Sanjiangyuan region in the future.
\end{abstract}

Keywords: Tibetan herders, rural development, provision of social services, Qinghai Province, education, health, conservation, globalization

\section{Introduction}

Situated in the centre of the Tibetan plateau, Yushu Tibetan Autonomous Prefecture in China is home to approximately 300,000 herders (pastoralists, nomads), farmers, and town dwellers. The three western counties of the prefecture that comprise the main study area, namely, Qumalai (Chumarleb), Zhiduo (Dritoe) and Zaduo (Zatoe) - cover an area of approximately $110,000 \mathrm{~km}^{2}$, about the size of Bulgaria or three times the size of Bhutan (Figure 1). Until recently, nearly $90 \%$ of the people were engaged in animal husbandry and depended almost entirely on the environmental resources in the headwaters of the Yellow, Yangtze and Mekong rivers for their livelihood and well-being.

(c) 2011 Foggin and Torrance-Foggin; licensee Springer. This is an Open Access article distributed under the terms of the Creative Commons Attribution License (http://creativecommons.org/licenses/by/2.0), which permits unrestricted use, distribution, and reproduction in any medium, provided the original work is properly cited. 


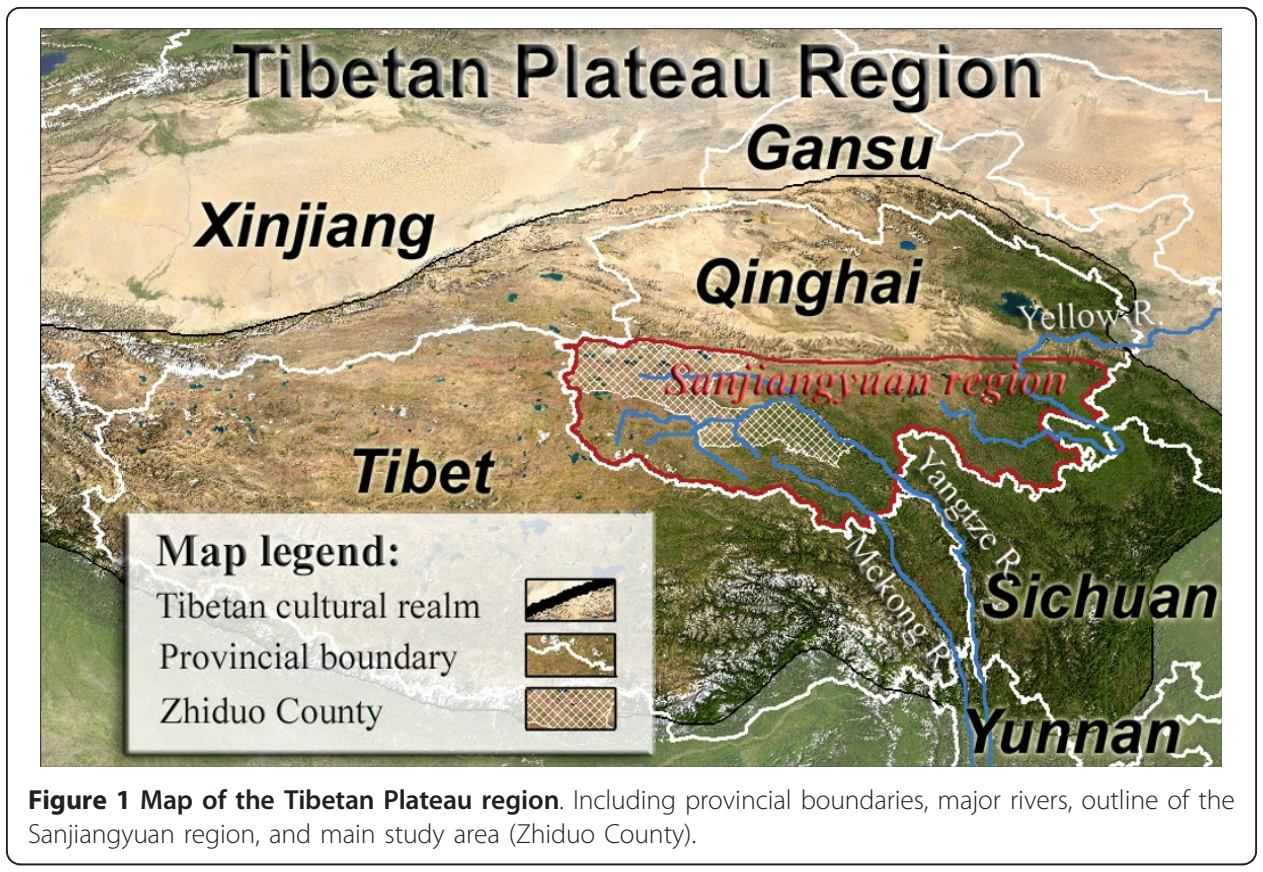

Historically, local communities were organized along clan lineages with a variety of collaborative resource management strategies and community support mechanisms. With the advent of the modern state, however, several new ways of providing social services were introduced and de facto trialled - including health, veterinary, educational and other services. Some of these models succeeded for a time, but few sufficiently integrated the unique socio-cultural considerations ${ }^{\mathrm{a}}$ or the political ecology $\mathrm{y}^{\mathrm{b}}$ of Tibetan pastoral society into the process of planning or the on-going execution/extension of social services. In some instances, the new approaches even called for the full abandonment of pastoral livelihoods, with a concomitant break-up of the very fabric and structure of local society. There is still a real need to develop more functional, culturally viable approaches for the provisioning of basic social services for Tibetan herders. When addressed together, improving access to social services and enhancing social equity (through a genuine involvement of local people in decision-making processes, giving them 'voice' in development) may jointly lead to greater empowerment and sustainability.

In many regions of the world, national governments have considered the extension of social services to remote or sparsely inhabited areas, such as found in the Tibetan plateau region, to be too problematic or prohibitively expensive. This view - often based on ideological premises - has been prevalent in arid zones extending from North Africa (Azarya 1996; Bennett 1988; Tignor 1971; Tignor 1976) through Central Asia (Bacon 1966; Leeuwen et al. 1994; Loomis 1988) and across much of northern and western China (Foggin 2000; Goldstein and Beall 1990; Taylor 2006; Vermeer et al. 1998; Williams 2002). All too often, varied forms and/or extents of sedentarization and urbanization have instead been promoted, despite the increasingly apparent societal costs and issues of (loss of) social equity (Blench 2001; HPG 2009; Xu et al. 2008b).

In southern Qinghai Province's Sanjiangyuan region, which includes all of Yushu Tibetan Autonomous Prefecture, rather than enhancing or expanding social services in 
rural grassland areas, China has been pursuing over the past decade a firm policy of relocation and settlement of herders. This has led to a radical transformation of the social landscape (as well as the physical landscape) with movement of tens of thousands of people to the periphery of small and medium-size towns or to newly created settlements. Such drastic changes in geography and livelihood, carried out mostly under the auspices of 'ecological migration' (shengtai yimin) policy, will affect not only local people's economic welfare, but also, just as importantly, many critical aspects of culture and society as well, including sense of identity, cultural continuity, and hope for the future (see (Wang et al. 2010) with responses by (Foggin 2011a; Wang et al. 2011) also see (Du 2006; 2009; 2010; Foggin 2008; 2011b; Galaty and Johnson 1980; Salzman 1980).

In response to such policy directions, the authors have already contended for several years that social services such as community health and education services can in fact be offered to pastoral communities, even in remote grassland areas (see, e.g. (DysonHudson 1985; Hodgson 2001; Swift et al. 1990)), both cost-effectively and without need for major socio-cultural shifts or significant changes in the herders' livelihoods. In addition, it is also suggested that national goals for the conservation (maintenance) of grassland ecosystem functions and the protection of endangered wildlife species of national interest (such as Tibetan antelope, snow leopard and black-necked crane) might be reached most effectively by working in partnership with local herders still living on the land (Foggin 2008; Foggin and Bass 2010). Thus, the dual goals of enhancing social services for herders and demonstrating in practical ways the conservation value of Tibetan herders in rural grassland areas may be pursued simultaneously. From a human development perspective, working to promote such rural community development can help to improve local people's well-being in situ as well as avoid some of the expected social costs (or challenges) generally associated with resettlement schemes.

In this context and for the above reasons, the authors have therefore sought to trial and demonstrate, or otherwise support and improve, the provision of social services in rural grassland areas of Qinghai Province - and thus to encourage adoption of viable alternatives to some current approaches to development and modernization, with greater sensitivity to pressing socio-cultural concerns, hopes, and aspirations.

Specifically, the authors present here a summary of their experiences and some of the lessons learned from the planning, implementation and regular assessment and evaluation of an integrated development project carried out in the headwaters of the Yangtze River since 1998. This brief review is also supplemented, through the text, with references to other relevant literature pertaining to key development issues.

\section{Methodology}

Several approaches have been adopted through the lifespan of the project described herein to determine and evaluate the effectiveness, appropriateness, value or success of the development model - rural extension of social services - and project interventions (specific programs and activities) introduced or trialled in the study area since 1998. A learning approach or mindset was adopted from the outset, in recognition of the fact that no one development approach or set of guidelines can be assumed a priori to be the best way forward for pastoral communities, in any given geo-political context, as such communities move into the twenty-first century - with its realities of modernization, of regional 
integration, even of globalization to the most distant regions of the planet. Mutual learning is necessary for the proper integration of traditional and modern approaches to animal husbandry and rangeland management, in order to develop better hybrid models of 'development' for herding communities. Such models should be based on pastoralists' wealth of experience, traditional ecological and other knowledge, and cultural preferences and aspirations, as well as on scientific findings and global experiences of development. For this reason, the authors have spent years learning about local views, perceptions, understandings, etc. through both formal and informal discussions, interviews with many stakeholders, focus groups, direct observation, and questionnaire surveys - in short, they have sought to learn much over the years simply by regularly 'drinking tea' (spending time) with local herders and other project partners.

Along the lines of grounded theory ((Glaser and Strauss 1967); Glaser 1993), a bottomup approach has thus generally been adopted in an attempt to understand multi-faceted local situations - purposely being driven more by facts in the field (through direct observation, listening to what people report, etc.) rather than by preconceived notions, desired outcomes, or theoretical frameworks. The underlying assumption is simple: there is much that can be learned from local people, and local people should have a more prominent voice in the matters that affect their lives (Cooke and Kothari 2001; Jaireth and Smyth 2003; Westing 1996). Thus no single research framework has provided overall guidance in this project, though many elements of participatory action research ${ }^{\mathrm{c}}$ have clearly played a key role. In short, action research is a pragmatic, learning-based iterative methodology and process that seeks to improve the ways in which selected issues are addressed and problems solved, in concert with a broader community of practice (Chambers 1983; Freire 1970; McNiff and Whitehead 2009; McNiff 2002).

For analysis and evaluation, a more specific framework was selected, one which by necessity is goal-oriented (Hansen 2005) based on the main purposes of the project evaluation, notably the establishment of program merit and improvement. For such purposes, (Fitzpatrick et al. (2004)) have recommended a 'formative' approach, with 'explanatory and actor models' most closely following the principles that likely will lead to enhancing the quality or appropriateness of program services. In our regular self-evaluation (and in this review), we have therefore focused most of our attention on maintaining regular interaction with and mutual learning amongst all key actors, with the aim of explaining both what has happened in the project and, as appropriate, why results or outcomes sometimes diverged from the predicted or expected scenario. The framework most akin to that used in this study is a balanced scorecard approach (Klassen et al. 2010) inasmuch as multiple factors or core concepts are considered simultaneously. The balance, however, is not between financial and non-financial outcomes, but rather the real-life impact of programs and activities across multiple sectors with special reference to four pillars of sustainability - economy, society, environment, and culture (cf. 'horizontal policy analysis', Foggin and Phillips forthcoming). Throughout the project, these pillars of sustainability repeatedly emerge, explicitly and implicitly, as critical to the emergence of more sustainable paradigms for regional development.

\section{Background: Tibetan herders in a globalizing world}

There are three main broad contexts that affect the lives and livelihoods of Tibetan herders: (1) local history and traditional socio-cultural practices, (2) government policies for 
development and conservation, and (3) global climate change. In regard to the first context, it is important to note that even while some level of adaptation may be recommended for people in all societies, there are still valid reasons why some communities or ethnic groups may choose not to change some or all of their traditional practices. Among Tibetan pastoralists, for example, community-based management of grassland resources has been practiced for many centuries. In the project area, this form of human organization clearly reflects some of the ecological requirements of a subsistence economy based on livestock grazing in arid zones and also the hunting of wildlife (such as Tibetan wild yak, antelope, gazelle) in the vast landscapes of the plateau. In some places, the practice of hunting also required long-distance tracking or pursuit of wildlife during seasonal migrations (Combe 1926; Foggin 2000; Mei and Zhang 2004). ${ }^{\mathrm{d}}$ Many such features of the socio-ecological landscape have helped to form the pastoral people of the Tibetan plateau (Ekvall 1968; 1974), and loss of their traditional ways of life will almost certainly lead to greater erosion of their sense of identity, certain cultural traits, and their overall well-being (Schech and Haggis 2000).

In more recent times, a number of government policies have also affected herding communities in the project area. With the introduction of animal husbandry and a commune system to the western areas of Zhiduo County in the late 1950s, the unit size for land management decreased considerably - first with the advent of simple cooperatives, then with the communes, and most recently with the adoption of a privatised household-level management structure that was transferred uniformly from lowland farming areas of China. The 'household responsibility (or contract) system' has been applied across the country including in high altitude grasslands since 1985 (Banks 2003; Ciren 2006; Richard et al. 2006). Yet despite such changes, there also still remains in most herding communities a strong sense of identity that goes beyond village-level elections, and recalls past tribal and clan affiliations. This has significant implications in terms of local leadership and community decision-making processes, on one hand, and the local acceptance and adoption of possible alternatives or variations on current land use (natural resource use) practices, on the other hand (Banks et al. 2003). Thus it is still important today to incorporate better understanding of local histories and cultural issues even in policy-led development interventions, to increase the likelihood of successful adoption of new measures by local community members (Foggin 2000; 2005a; b).

Also in relation to government policy, globalization equally affects communities in tangible ways because, from their perspective, all high-level decisions are 'external' and outside of their normal existence, of daily life decisions (Comaroff 2009). The impact of regional/national policies on local herders has increased most rapidly over the past few decades, particularly with expansion and integration of communication and transportation infrastructure as well as active promotion of development goals across the country (Foggin 2008; Foggin and Phillips 2010).

A third important factor affecting Tibetan herders, whether recognized by them or not, is climate change. As illustrated in the documentary work of Asia Society (http://www. asiasociety.org/chinagreen) the environment is changing rapidly in China - perhaps most rapidly, in some respects, on the Tibetan plateau. In addition, environmental/climatic changes on the plateau affect not only local herders and farmers, but indeed millions of people downstream (see (Economy 2004)). With many major rivers arising from the Tibetan plateau, nearly 40 percent of the world's population now depends on, or is directly 
influenced by, the current state of the environment on the plateau (Foggin 2008; UNEP/ GRID-Arendal 2007).

Local decisions and national policy are thus interlinked - reflecting an increasingly integrated and globalized world (Zhao (2009)). further explains the significance of the plateau: 'Meteorological scientists warn that [environmental changes on the plateau] may have implications beyond Asia's river basins, as shifting dynamics of the atmospheric circulatory system over the plateau could change wind and monsoon patterns across much of the world. There is still no model to predict what will happen, but there's plenty of evidence to warrant immediate action to avoid a crisis that would imperil billions of people across Asia.' This means that rapidly melting glaciers, changing rainfall and snowfall patterns, decreasing flows of rivers, etc. - all of these point toward an uncertain future. ${ }^{\mathrm{e}}$ With little voice available to them, such uncertainty (which stems from multiple sources, climate change and otherwise) has led to increasing levels of individual and corporate anxiety for Tibetan herders as they face an unknown future driven largely by external agents of change.

The project described herein, with its varied programs and activities, has aimed from the beginning to enhance the involvement of local stakeholders in the development changes occurring around them, and to support local people and communities as they transition into what is already, de facto, a globalized world.

\section{Background: the project players}

The leaders of the integrated development project described herein are an ecologist and conservation biologist (Foggin) and a consultant paediatrician with speciality in community child health (Torrance-Foggin). The project provided the basic context in which more community-oriented approaches to the provisioning of social services and environmental protection in pastoral environments were trialled, in contrast to the more top-down, blueprint approaches oft developed in distant offices.

To enable this work, which was first envisioned with local colleague Zhaxi Duojie, the authors established a non-profit organization in Canada, Plateau Perspectives (http:// www.plateauperspectives.org) with a mission 'to promote sustainable community development and environmental protection in the Tibetan Plateau region of western China.' Around the same time, Zhaxi Duojie (also known as Zhaduo) established the Upper Yangtze Organization (Figure 2), a grassroots endeavour comprised mostly of local herders. ${ }^{\text {f }}$ The two organizations began their partnership by carrying out conservation and development activities together on an ad hoc basis (1998 to 2002). This was then followed by more proactive collaboration with the government of Zhiduo county, under the tripartite Yangtze Headwaters Sustainable Development Project (2003 to 2008). Similar work has also continued to the present, supported largely by NORAD (Norwegian Agency for Development Cooperation) and the Ford Foundation, with both new and on-going partnerships developed or maintained - with local communities, local government, provincial universities and research institutes, and the Sanjiangyuan National Nature Reserve. Such partnerships have ensured that the authors could hear (and sometimes also participate in) a wide range of discussions and opinions about approaches to development, with a special focus on the high grassland regions of the province.

Through our field operations, we have also seen the development of a network of local communities in the headwaters of the Yangtze and Mekong rivers interested in 


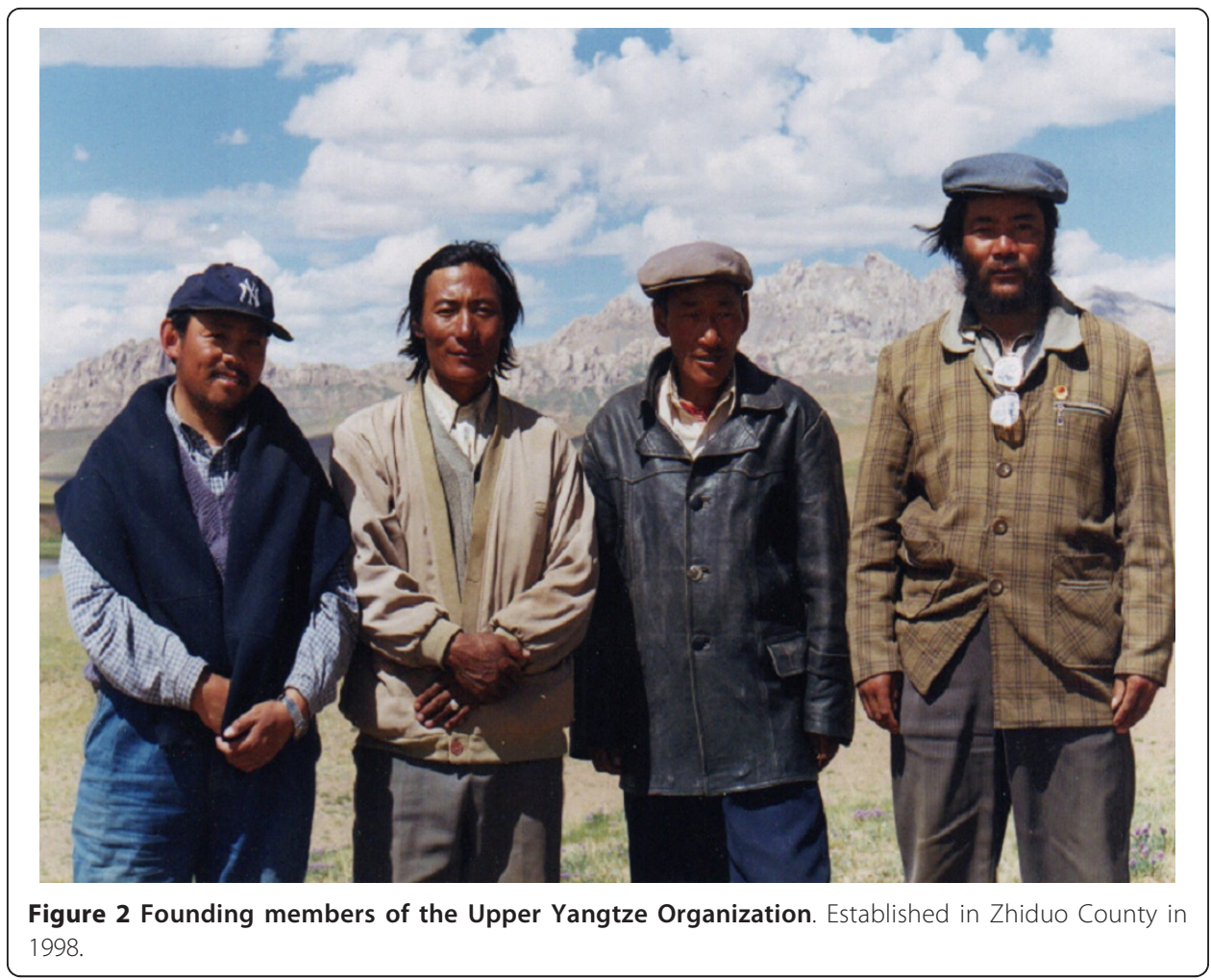

conservation and development ventures - some embryonic, some more developed, but all committed to greater involvement in these important matters. On the basis of initial successes, we have equally noted that some provincial government authorities are beginning to adopt a new view with respect to conservation, namely to value the role that 'community co-management' could play regionally in the management and conservation of natural resources. Additional information about these and of other conservation or sustainability-oriented initiatives in the region can also be found in (Breivik (2007); Cyranoski (2005); Foggin (2010); Foggin and Bass (2010); Hao (2008); McBeath and McBeath (2006); Morton 2007a; b; Phillips (2009)) and (Shao et al. (2006)).

\section{Yushu Integrated Development Project}

The Yushu Integrated Development Project is based on a wide array of friendships and partnerships and recognizes the value of regular, continuous learning. ${ }^{g}$ With many possible areas of assistance, overall project direction was initially given by partners resident in the project area. Three main categories of interventions were suggested, in the following order of importance: health, education, environmental protection. Health care is assumed to bring most immediate benefit; education is understood to help prepare the present and next generations for leadership; and environmental concerns, although recognized as important, were considered to be less tangible or of immediate interest by most community members. In subsequent years, however, it became increasingly apparent to many people that even matters of environmental management may have direct bearing on their well-being, not least with increasing human-wildlife conflict and through positive and negative impacts arising from the establishment of protected areas and from environmental policies. All three of these program areas have therefore constituted, at different times 
in the life of the project to date, a significant part of Plateau Perspectives' and its partners' development work in the region.

\section{Project goals}

In initial conception, the project sought to improve people's 'quality of life' through standard development inputs in health care and education. However, even in the early design stage, with sweeping changes already affecting (or potentially affecting) the lives of Tibetan herders in the project area - not least, government programs and policies encouraging people to move away from a grassland-based livelihood and into new towns, with limited opportunities for employment - a new theme, indeed a new overarching goal or purpose, began to emerge for this integrated development project. Not only were improved social services and environmental conservation to be explicit project goals, but now also the practical demonstration that herders (a) can live sustainably on the land, not harming the natural environment (and indeed, they can assist and promote biodiversity conservation), and (b) can be provided with good quality social services, including health care and education, without necessity to relocate away from their traditional homes in rural grassland areas. The latter is in fact one of the primary foci of this paper - namely, a review of how social services, particularly health and education services, have developed in the project area over the past decade, with the support of local government, in situ in a remote grassland community of Yushu Tibetan Autonomous Prefecture.

\section{Project interventions}

The main interventions introduced in this paper are the project's efforts (1) to improve access to and quality of education and health care for rural herding communities, and (2) to enhance genuine cooperation between governmental conservation authorities (including protected area management bureaus) and local communities, such that both parties may benefit from such arrangements. Through this process, local herders may also be increasingly recognized as stakeholders that make a positive contribution to environmental goals, rather than seen as harmful for the environment, as all too often has wrongly been assumed (Aronson 1980; Bennett 1988; Ellis and Swift 1988; Schneider 1981; Tserendash and Erdenebaatar 1993).

\section{Basic education}

In the two separate cases in which village education was supported by the project, one community succeeded and the other failed (at least temporarily) in establishing and maintaining a village school as their indigenous (locally owned) project (see Table 1). In the first instance, community members initially did not value education, wondering how it could or would contribute to the betterment of their children's future. They were, after all, 'only (and always) nomads.' However, after more than a year of discussion and debate within the community, encouraged by Plateau Perspectives together with Zhaxi Duojie, the community began to shift... and they soon considered that for their future, it would indeed be best if they could now begin to produce 'their own leaders.' Thus they began to see value in obtaining more formal education, even if the process would be generational in timeframe. For the first several years, a simple tent school was established (Figure 3), which moved several times as community members tried to agree on 
Table 1 Indicators of community involvement and success within three main program areas

\begin{tabular}{|c|c|c|c|c|}
\hline & $\begin{array}{c}\text { Village school } \\
\text { A }\end{array}$ & $\begin{array}{c}\text { Village school } \\
\text { B }\end{array}$ & $\begin{array}{l}\text { Village } \\
\text { clinics }\end{array}$ & $\begin{array}{l}\text { Collaborative } \\
\text { management }^{\mathrm{a}}\end{array}$ \\
\hline \multicolumn{5}{|c|}{ Local ownership and participation in development initiatives } \\
\hline $\begin{array}{l}\text { Initial discussions held by } \\
\text { community }\end{array}$ & $\sqrt{ }$ & $\sqrt{ }$ & $\sqrt{ }$ & $\sqrt{ }$ \\
\hline $\begin{array}{l}\text { Key start-up decisions by } \\
\text { community }\end{array}$ & $\sqrt{ }$ & $\sqrt{ }$ & $\sqrt{ }$ & $\sqrt{ }$ \\
\hline $\begin{array}{l}\text { On-going management by } \\
\text { community }\end{array}$ & $\sqrt{ }$ & - & $\sqrt{ }$ & $\sqrt{ }$ \\
\hline $\begin{array}{l}\text { Local decisions re materials } \\
\text { purchases }\end{array}$ & $\sqrt{ }$ & - & $\sqrt{ }$ & $\sqrt{ }$ \\
\hline Involvement of community NGO & $\sqrt{ }$ & - & $\sqrt{ }$ & $\sqrt{ }$ \\
\hline Production of participatory video & $\sqrt{ }$ & $\mathrm{n} / \mathrm{a}$ & $\sqrt{ }$ & $\sqrt{ }$ \\
\hline Local voices heard at roundtables & $\mathrm{n} / \mathrm{a}$ & $\mathrm{n} / \mathrm{a}$ & $\mathrm{n} / \mathrm{a}$ & $\sqrt{ }$ \\
\hline \multicolumn{5}{|l|}{ Measures of project sustainability } \\
\hline Continued staffing & $\sqrt{ }$ & $\sqrt{ }$ & $\sqrt{ }$ & $\sqrt{ }$ \\
\hline Continued attendance & $\sqrt{ }$ & - & $\sqrt{ }$ & $\mathrm{n} / \mathrm{a}$ \\
\hline Middle School achievement & $\sqrt{ }$ & - & $\mathrm{n} / \mathrm{a}$ & $\mathrm{n} / \mathrm{a}$ \\
\hline Salaries provided by government & $\sqrt{ }$ & $\sqrt{ }$ & $\sqrt{ }$ & $\sqrt{ }$ \\
\hline \multicolumn{5}{|c|}{ Recognition of the value of rural development local voices by higher-level authorities } \\
\hline Local partnerships with SNNR ${ }^{b}$ & & $\sqrt{ }$ & $\sqrt{ }$ & $\sqrt{ }$ \\
\hline Qinghai Forest Bureau and $\mathrm{GEF}^{\mathrm{C}}$ & & $\sqrt{ }$ & $\sqrt{ }$ & $\sqrt{ }$ \\
\hline QASS International Symposium ${ }^{d}$ & & $\sqrt{ }$ & $\sqrt{ }$ & $\sqrt{ }$ \\
\hline
\end{tabular}

a Several forms of collaborative management are being trialled in the project area, including 'community comanagement' and 'contract conservation,' to promote more sustainable utilization and conservation of natural resources, including wildlife species. Local people also can engage in various forms of community development, so long as the environment is not degraded. ${ }^{\mathrm{b}}$ The Sanjiangyuan National Nature Reserve (SNNR) is now one of the key proponents of the value of working closely with local herding communities. ${ }^{c}$ Based on collaborative work begun in the Sanjiangyuan National Nature Reserve, the provincial Forest Bureau is now in the final stages of preparation for a large-scale project that may receive support from the Global Environment Facility (GEF). The development of genuine partnerships with herding communities is central in the proposed project. ${ }^{\mathrm{d}}$ The Qinghai Academy of Social Sciences (QASS) recently hosted the International Symposium on the Human Dimensions of Ecological Conservation on the Tibetan Plateau, from 21 to 26 September 2011. This significant meeting drew together professionals and government leaders from China and abroad to discuss how the social elements and the natural/physical elements of sustainability could become better integrated.

the best location. Long discussions were held, often lasting well into the night. But the final outcome was that the local school became their school; locally owned, not a foreign school project. A need for change had thus been noted, and by allowing sufficient time for the community to make its own decision, the village school remained a communityowned and -operated venture. ${ }^{\mathrm{i}}$

In contrast, in a neighbouring village, although the community began on a similar path, their sense of ownership disintegrated when the project was co-opted by a higherlevel government bureau together with a different external (foreign) non-government organization. Even the colloquial name of the school quickly changed - from being recognized as the community's own school, to being called 'the school belonging to the foreign organization'. Following such a change in ownership, local support for the school eroded rapidly, few families continued to send their children, and school property maintenance all but ceased. Once a pride of the community, it lost its direction and purpose... until the over-bearing presence of external agencies ceased, at which point the community once again took more of a lead role and the project began afresh. The erosion of local ownership of the school had occurred as the community's involvement in decisionmaking was decreased (the school became a top-down project with little consultation 


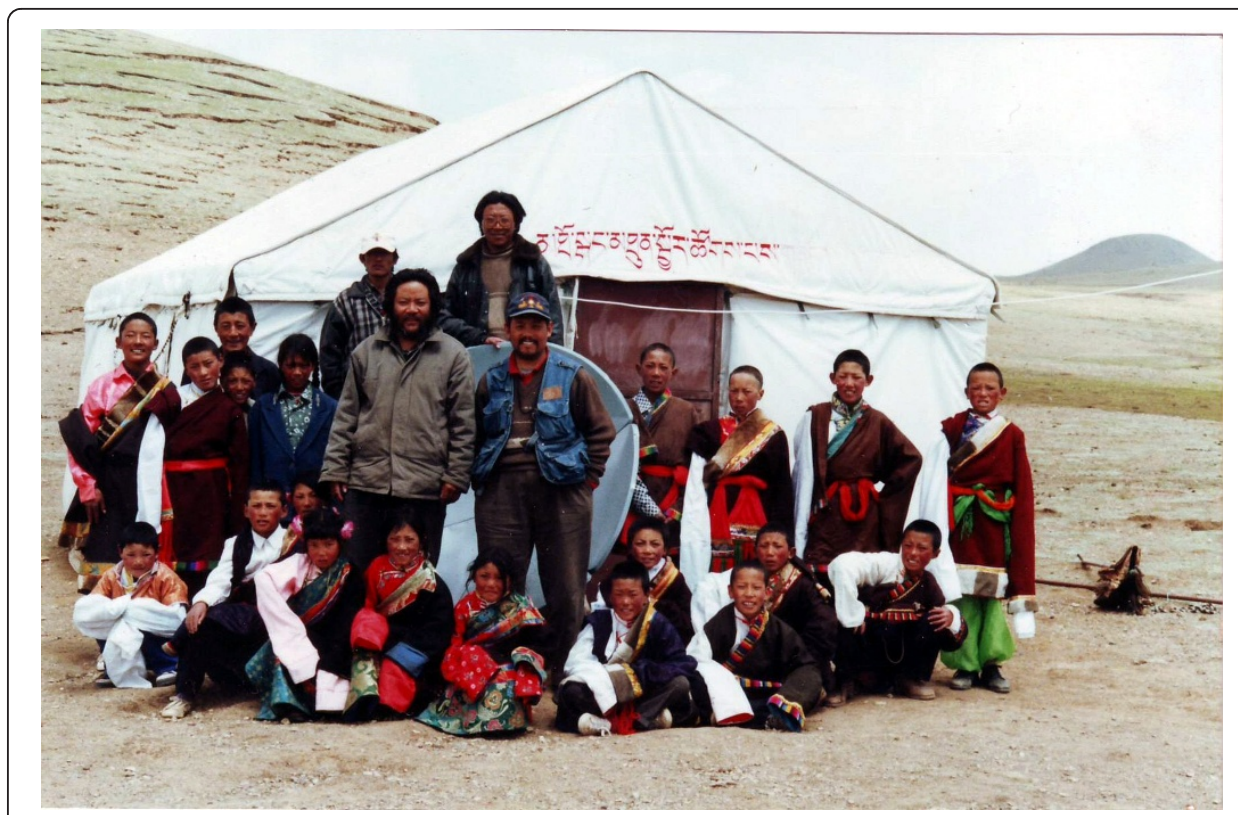

Figure 3 Muqu village school in its original location. Founded with assistance from the Upper Yangtze Organization and Plateau Perspectives in 2000.

with community members, decisions were made by others, and inappropriate supplies were purchased in distant locations) and as leadership of the school transitioned from being the responsibility of trusted local community leaders to impersonal government agencies and external organizations (Cardenas et al. 2000; Vollan 2008).

Some of the above processes of community development are documented well in a 'participatory video' created by one of these communities. Filming was facilitated by Insight, working together with Plateau Perspectives and the local Upper Yangtze Organization. In this video, the community members speak in their own words. An abridged version of the community-directed (participatory) video can be found at http://www.insightshare.org/video_ladakh.html.

Depicting both hope and despair, the short film not only introduces local perceptions and realities to outsiders, but - as with any good community development work - the process itself, of creating the video, also was a valuable exercise in giving local people more voice, in increasing their involvement in development and contributing to decision-making processes.

\section{Community health}

In 2003, Plateau Perspectives launched its health program in collaboration with the county health bureau and the grassroots Upper Yangtze Organization. Several local communities as well as the county health bureau had sought Plateau Perspectives' assistance to carry out this work, and we believe it has shown good potential in the first few years of implementation to bring positive impact to rural communities. In this paper, however, although we describe the main inputs and activities, we seek not as much to provide a specific template that can be replicated, but rather to highlight the fact that such services can be provided in rural settings - and thus, not require of pastoralists that they relocate to urban settings to receive adequate care (Table 1). 


\section{Training village doctors}

With high levels of trust placed in local doctors, one of the main original requests from local communities was to train (provide refresher courses for) village doctors, to help them better diagnose and treat common conditions as well as to gain better understanding of western medicines and their side effects in order to improve health care and avoid inappropriate use of medication (Figure 4). Training courses included discussion of methodologies to enable communities to seek and discover new ways to improve their health; disease prevention, with a focus on the commonest illnesses, the most serious preventable diseases, and the uptake of immunizations; the management, transport and administration of immunizations; and women and children's health, including the early detection and management of problems in pregnancy and delivery.

\section{Training women's health workers}

In response to a request from the health bureau, young women from many villages in the project area also came for training in women's health work (around 25 women in Zhiduo County, and 15 women in Zaduo County). Training modules were given by two doctors and a midwife. The students enjoyed the course, participated well (e.g. writing health songs and engaging in role play), and made considerable progress in terms of knowledge and skills gained during the 3-week workshops. Some of these women were also later invited to village meetings (usually attended only by men). Further training of women's health workers has been requested, as there is still a great need to train some of them to a higher level. Yet even now, the women trained are already recognized as a new kind of health worker, better attuned to the specific needs of mothers and children, and of women in general. Many of the trainees also received teaching from the Centre for Disease Control on how to give immunizations, as suggested by one local community

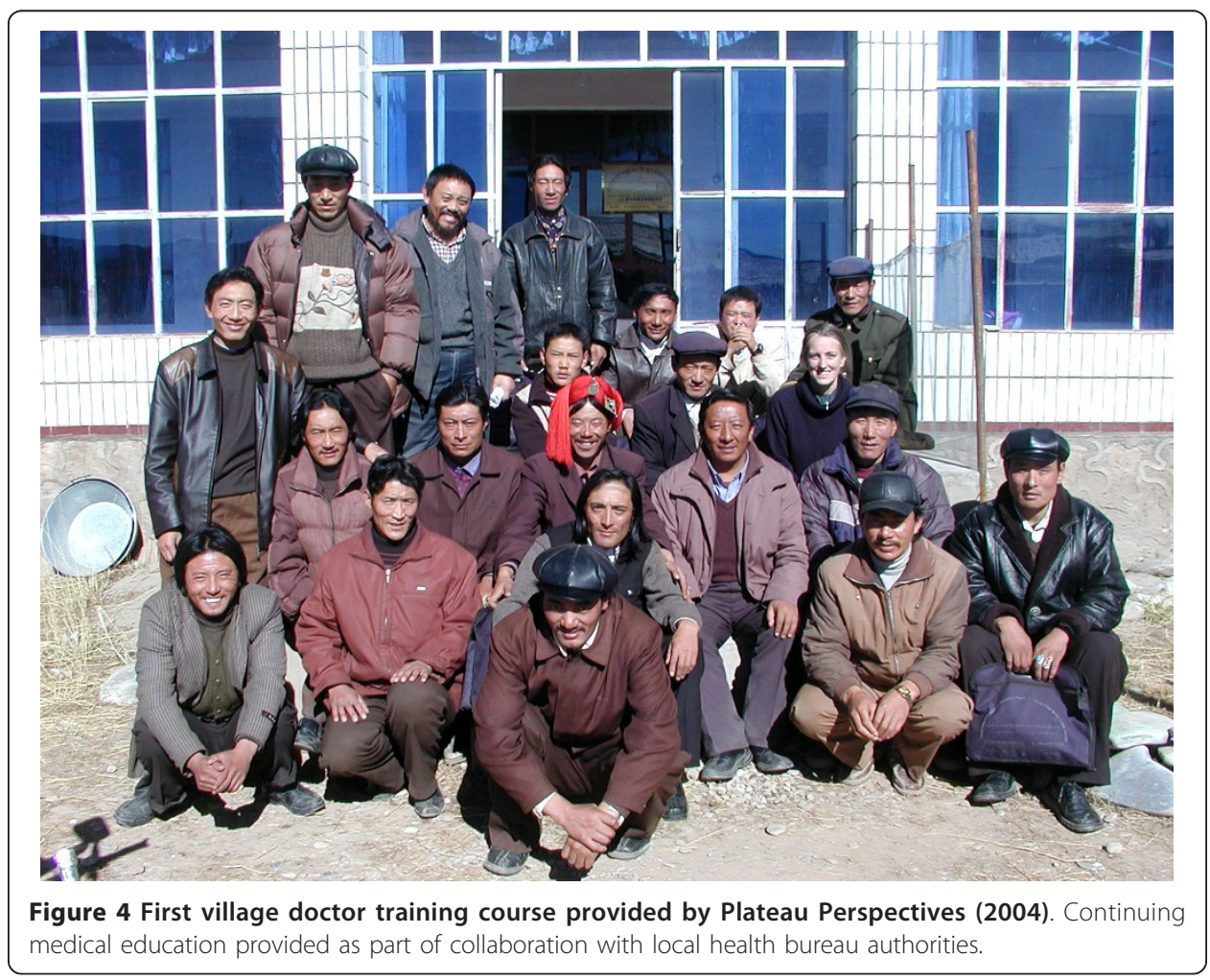


leader as means to encourage young women by demonstrating some of the benefits of formal education and to increase immunization coverage.

\section{Village clinics and the national health insurance scheme}

When a request came to assist with the construction of village clinics, the authors' first question pertained to how this might, or might not, improve the health of the community, or the quality of health care provision. However, both the community leaders and the health bureau put forward several strong arguments in favour of our participation in such an intervention, which largely have been proven correct.

First, for most people and most conditions, the county hospitals (even the township clinics) were inaccessible. The most accessible level for most herders was the village (dadui). At that level, therefore, local leaders appointed the best trained doctor from each area, and salaries provided so that the doctors could always be available. With construction of a clinic building, the health bureau equally began to administer the payment of medical bills through the national health insurance scheme. Village clinics also are used to facilitate the storage and proper administration of medicines. In this way, greater availability of carefully selected medicines can assist the doctors personally, by decreasing the frequency of visits to town required for them to maintain adequate supplies of medicines.

Secondly, several leaders also suggested that the village clinics would likely become community centres with a broader suite of programs. They also offered that a village committee should organize the purchase and sale of medicines, so that the doctors' prescribing habits would be unaffected, as they no longer would be able to receive personal gain from this practice. In these and other ways, by listening and respecting local opinions, participation in the development and building of village clinics also provided a platform or avenue through which the project has been able to support and strengthen local community leadership.

Over the past few years, the health bureau and village (dadui) communities have consistently appointed the best doctors from the training courses, and have generally continued to run the clinics in such a way as to leave the doctors free to see patients. In addition, by adding only a small increase to the price of medicines (to pay for transport and clinic operating costs) several villages are now running the clinics at no loss, and utilization rates are high. Most of the village clinics have thus proven to be more successful than any of the project partners had predicted and most village doctors remained highly motivated and invested in improving the health of the people from their own community.

Of the clinics supported, there was also a range of success. The most successful measured in terms of number of patients seen, maintenance of the pharmacy, and the reliable presence of doctors - were all those in which the community had proactively requested assistance for establishing a local clinic.

In contrast to some of the noted effects of relocation and settlement in towns, the people who can receive medical care in the countryside benefit not only in terms of socio-economic advantages (as evidenced in lower costs through the national health insurance scheme), but also in cultural terms as they are not forced to give up their traditional way of life and social network in order to access social services.

\section{Environmental protection}

In the context of recent/current development policy in the province, not only are the challenges associated with the provision of social services for pastoral communities 
given as one of the key reasons to settle herders in town, but also conservation (or environmental protection) is raised as a critical issue and rationale for settlement. Yet pastoralists can also be amongst the strongest allies in conservation efforts, residing year-round in or near ecologically important habitats and able to provide regular monitoring services that could not be achieved through other means. This reality has been demonstrated in the present project, with increasing support now given by the provincial forestry bureau and its nature reserves for 'collaborative management' as a key conservation strategy (Foggin 2010; 2011b). As such, environmental work may in fact have multiple impacts, not just environmental (Foggin and Phillips forthcoming).

The specific conservation goals of the project have been twofold: to demonstrate the positive contributions that can be made by local herders for the protection of endangered wildlife species (Figure 5), and to help mitigate increasingly serious human-wildlife conflicts that are occurring in the project area. The former seeks both to increase the conservation workforce and to affect people's attitudes about herders and pastoral livelihoods, including attitudes of policy makers, planners, and decision-makers. The latter seeks to minimize financial loss to the herders, on one hand, and to avoid a potential erosion of local people's support for conservation, on the other hand. ${ }^{\mathrm{k}}$

Project inputs included raising environmental awareness, local capacity building, applied wildlife research, and support for enhanced protected area management. Local herders have participated in much of this work, including their increased involvement in decision-making processes, for example through a visible presence at strategic roundtables, workshops, etc. that have helped them bring their ideas and opinions directly to policy advisors and leaders who make key program decisions.

The authors and Plateau Perspectives equally have worked with the Sanjiangyuan National Nature Reserve since 2005, introducing more people-oriented approaches with a special focus on 'community co-management' of natural resources (Foggin 2005a; 2005b; 2010; Foggin and Bass 2010) (Figures 6 and 7; Table 1). In practice, a team of local herders has been strengthened, with key responsibilities ranging from raising local environmental awareness at community gatherings (e.g. during school holidays and annual festivals); to anti-poaching patrols; to the regular monitoring of

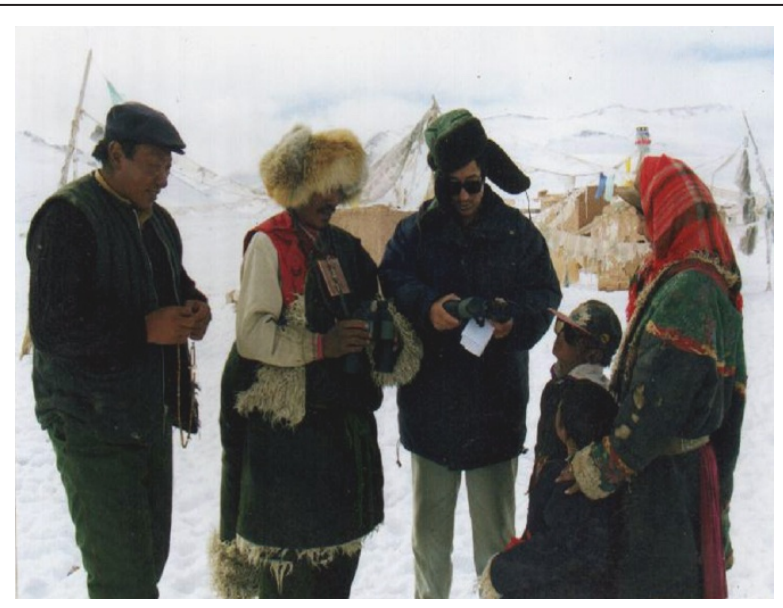

Figure $\mathbf{5}$ Local wildlife monitors. Initially supported by Plateau Perspectives and Upper Yangtze Organization, later also by Sanjiangyuan National Nature Reserve. Photograph by Zhaxi Duojie (2004). 


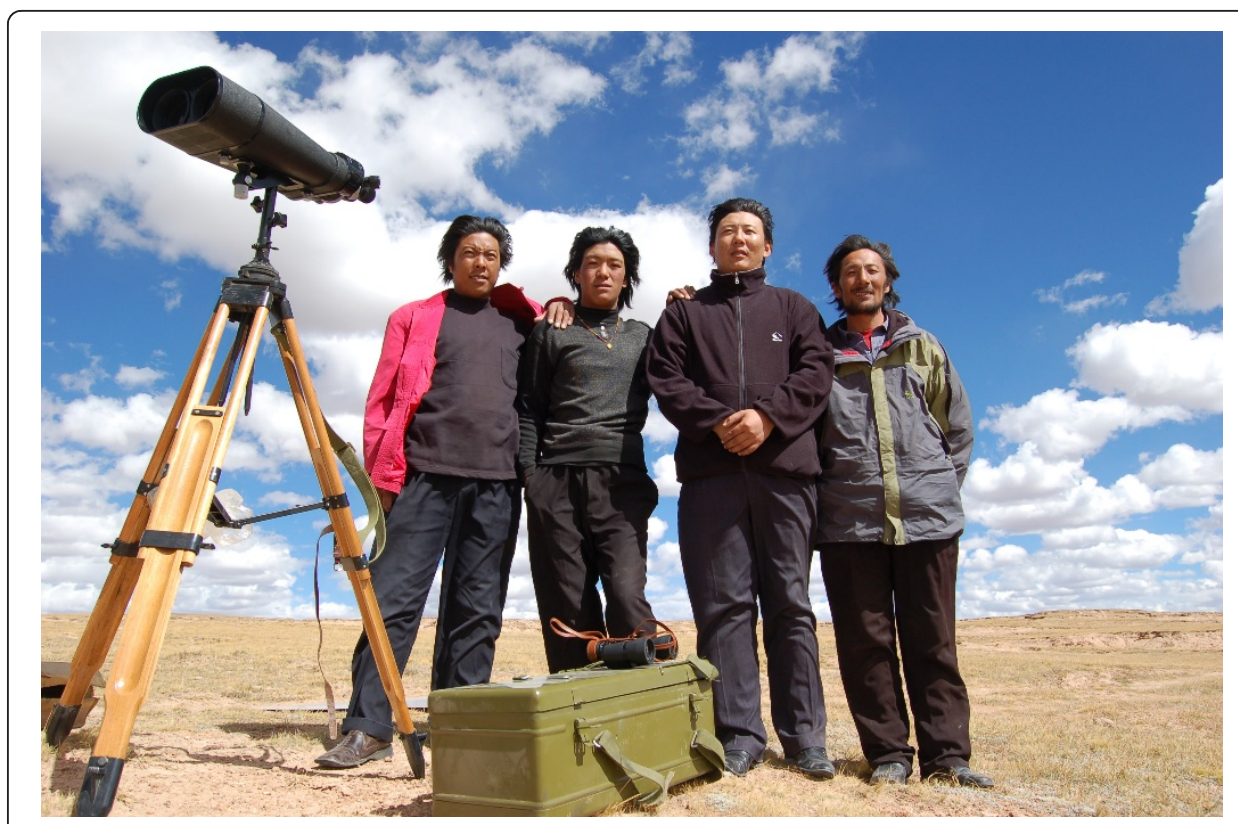

Figure 6 Joint wildlife monitoring (on-site training) in the Cuochitan wetland. Fieldwork undertaken after a multi-stakeholder planning meeting held at the Suojia Station of the Sanjiangyuan National Nature Reserve in October 2007, marking the formal start of a community co-management project in the Suojia area.

wildlife including Tibetan wild ass, wild yak, black-necked crane, and snow leopard (Figure 8). Several planning meetings and training workshops have been organized, cohosted by the nature reserve, to assist with species identification and monitoring protocols as well as data collection, analysis, storage, and retrieval. In addition, binoculars,

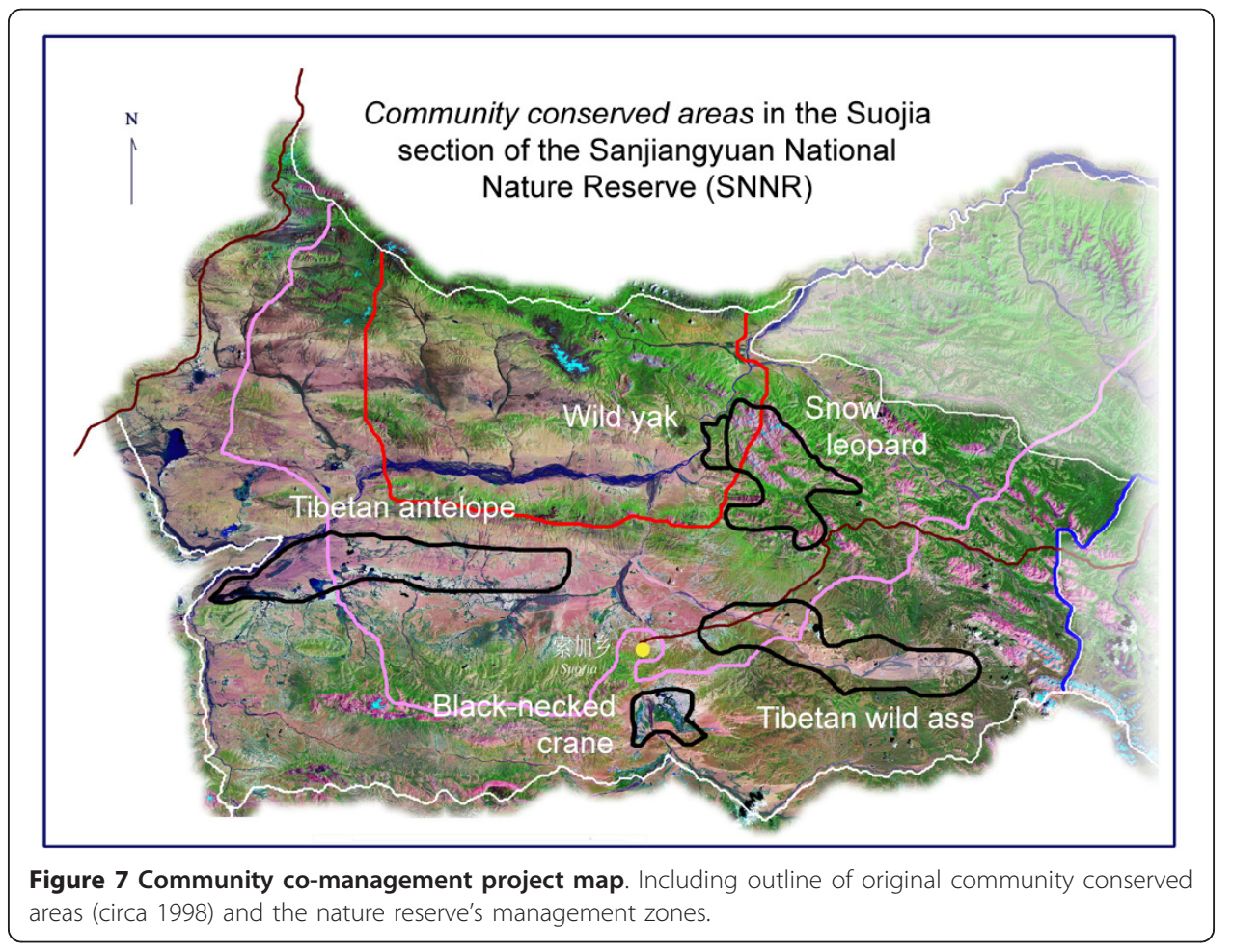




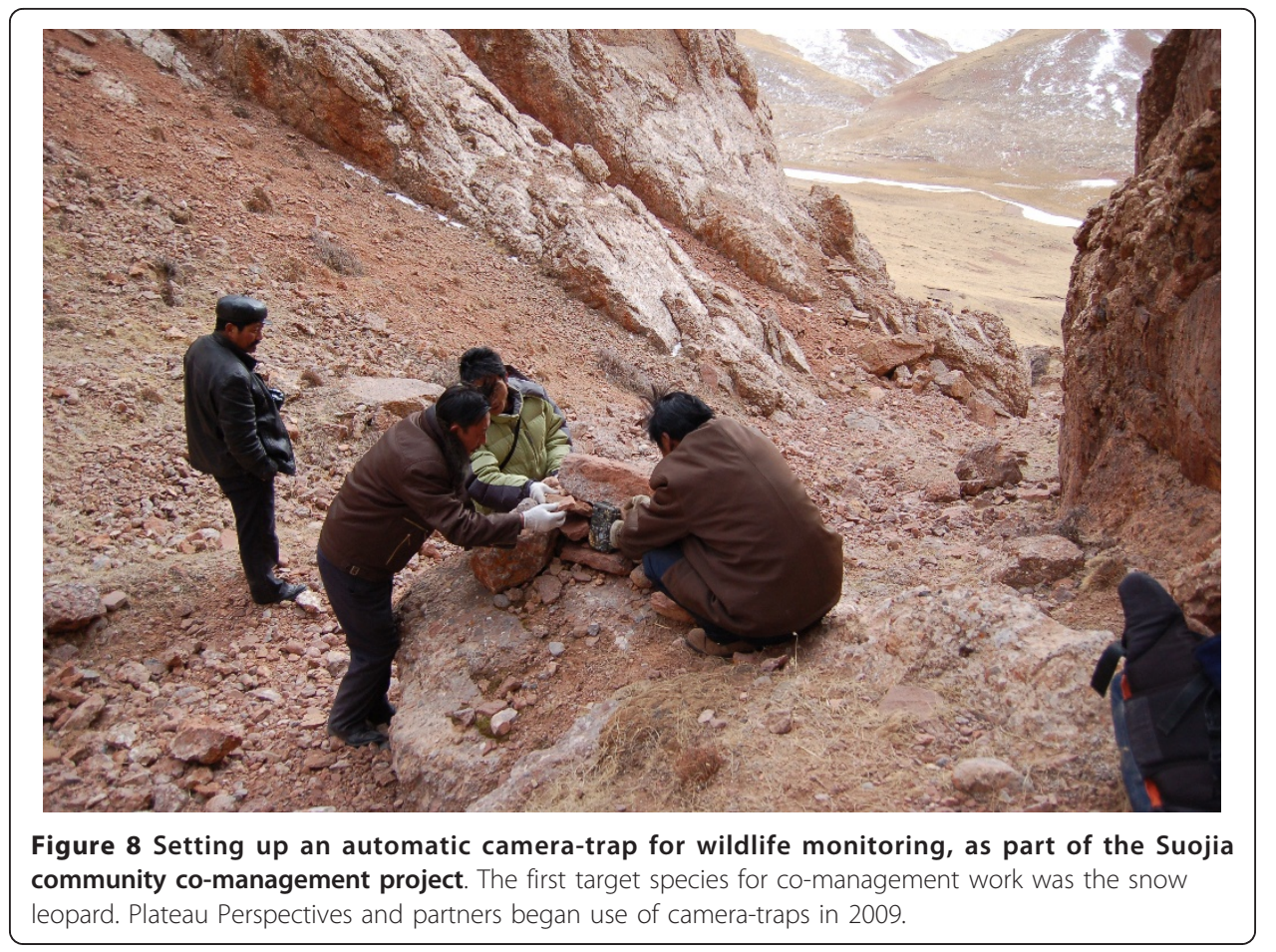

cameras, outdoor clothing, and ID badges (to indicate the wardens' authority to carry out their duties) have also been provided. All these inputs and activities over the past few years appear to have laid a good foundation for genuine cooperation between local communities, government, and external agencies (which can provide expertise, facilitation, and/or funding), through some form or other of collaborative management.

\section{Discussion and conclusion}

The sustainability of rural communities in much of Qinghai Province is premised on the economic and ecological functions of, and the social networks developed in, the high altitude temperate grasslands. Environmental services must be maintained, not only for the local pastoral population, but also for millions of people downstream who equally depend on the proper ecological functioning of the Tibetan plateau's vast grasslands. Much current development policy in the area therefore seeks to remove local herders from their traditional lands, in the belief that relocation and settlement of Tibetan herders will improve the government's ability to provide social services and help to protect the environment. The former rationale, however, may be inadequate, as international experience has shown overall health and well-being of relocated/settled communities, especially of ethnic minorities, rarely to achieve expectations; and environmental conservation may best be achieved by working with local communities still residing in rural grassland areas.

The project described in this paper has shown that social services can in fact be provided successfully even in remote herding communities. It also has shown that local herders can contribute well to multi-partner conservation efforts, and in fact they may be essential to their success. Together, these observations counter some assumptions about 'development' such as the belief that social services can only be provided well in urban 
areas, that settlement is necessary for health and education to improve, and that herders are generally harmful for the environment - in fact, the contrary has been demonstrated.

One of the overarching themes of the authors' work has been to give local people and communities in the project area more voice (see (Foggin 2011a; Wang et al. 2011)), thus greater opportunity to be involved in the decision-making processes that affect their lives. Local people should be seen as part of the solution, not the problem; yet still this is rarely recognized in practice. The development work carried out by the authors has contributed toward increased sustainability in the region by adopting an approach that supports the integration of people and place, of development and conservation, and encourages collaborative management (co-management). The project also worked with a large number of administrative levels and sought to promote partnerships within and between different agencies and bureaus. All of these factors help to promote sustainability, as more stakeholders become involved in the process of community development and conservation.

Perhaps the most specific success of the project has been its influence on shaping environmental policy through its work with nature reserves - by introducing and trialling in a specific local context more people-centred, collaborative approaches to natural resource management and wildlife conservation. Such an approach benefits not only environmental goals, it also has contributed to greater social equity - both of which in turn can help to enhance the sustainability of local pastoral livelihoods.

From the beginning of their involvement in the region, the authors have sought to support local initiatives rather than simply appropriate local participation in support of external objectives (see (Cooke and Kothari 2001; Ghai and Vivian 1992; Pretty 1995)). This has often meant that activities progress more slowly than desired (since project activities should proceed at the speed of the community, rather than a funder-driven rate), however it also has increased the likelihood that project outcomes will remain sustainable and replicable (Taylor-Ide and Taylor 2002; Jaireth and Smyth 2003; Velasquez et al. 2005). Underpinning this community-focussed approach is the sense of ownership and empowerment gained at the grassroots level when local voices are heard, and when financial costs (and other inputs) are shared between partners (for example, both materials and partial funding were supplied by local communities in the building of the village schools and clinics described herein).

With regard to the financial sustainability and replicability of the project, while a number of donors and other external players have assisted in the overall program and specific activities, the total financial contribution has been relatively modest by international standards - and indeed, but a small fraction of the cost of provincial or national initiatives in the region. Moreover, the significance of enabling local people to be 'given a voice' far outweighs, in terms of positive impact on sustainability, the relatively small funds that were made available through the authors' work.

Finally, as outlined at the LEAD International Session in Beijing in November 2009 (http://china2009.lead.org, also http://www.lead.org), there are several important categories of adaptation-oriented development interventions that every development program would do well to incorporate - most of which the present project has already addressed in various ways - including (1) integrated natural resource management, (2) incorporation of traditional wisdom, (3) poverty alleviation, (4) preservation and restoration of natural ecosystems, and (5) regional cooperation for planning and decision-making. When these 
factors are integrated into development programs and projects, not only do local communities benefit in the short-term, but the long-term resilience of human-ecological systems also may be strengthened (Berkes and Folke 1998; Stevens 1997). In sum, through provision of social services in situ (in grassland areas), and with the introduction of more collaborative forms of natural resource management, local herding communities may benefit from improved socio-economic conditions, better conservation of wildlife, enhanced sustainability of livelihoods, and a sense of empowerment.

\section{Endnotes}

${ }^{a}$ In the Tibetan plateau region, unique socio-cultural considerations include, for example, pastoral livelihoods that have been adapted to high altitude grasslands, sparse population density, and a harsh, unpredictable environment. Social and cultural identities can and do develop through such environmental situations, as described well by (Ekvall 1968; 1974) and (Goldstein and Beall 1990; 1991). Other social development research has shown how cultural continuity (i.e., the maintenance or development of cultural identity), or the lack thereof, also can affect the outcome of development policies, programs or interventions (Chandler and Lalonde 1998; 2008; Foggin 2011a; Foggin and Foggin 2008; Lalonde 2003).

b'Political ecology' is the study of relationships between socio-political and economic factors with environmental issues such as land degradation, conservation policy, conflict over natural resources, etc. The classic Fate of the Forest (Hecht and Cockburn 1990) is an excellent example of political ecology in the socio-cultural and ecological context of South American rainforests, rife with competing interests, power plays, and the marginalization of local/indigenous communities. Also see (Spooner (1973)) for a treatise on the cultural ecology of nomads/pastoralists (Breivik (2007); Ho (1998)) and (Yeh (2000)). provide some examples of political ecology studies in western China.

'Participatory Action Research should not be confused with Participatory Rural Appraisal, a fact-finding and assessment technique often used in international development.

${ }^{\mathrm{d}}$ Also see (Huber 2003; 2005) and (Norbu and Simmons (1997)) for a lengthier discussion about hunting practices as well as cultural values and perceptions regarding hunting in the Tibetan region.

${ }^{\mathrm{e}}$ See (Eriksson et al. (2009); Morton (2008); Polycarpou (2010); Xu et al. (2009)) for more details. Also see 'Rivers of Ice/Glacier Research Imaging Project,' hosted on the Asia Society website (http://sites.asiasociety.org/riversofice/about).

${ }^{\mathrm{f}}$ In subsequent years, several other non-profit organizations have been established in Yushu as well, including for example the Snowland Services Group, Friends of the Wild Yak, Snowland Great Rivers Environmental Protection Association, and Kunpen Vocational Training Centre.

${ }^{\mathrm{g}}$ In order to determine how best to assist local herding communities to improve their quality of life, a needs assessment was carried out at the beginning of the project, followed by a prioritization of several potential development interventions. This prioritization was undertaken with local colleagues and other stakeholders, both individuals and organizations. Over a period of two years, both authors also listened attentively to the community and discussed their beliefs, hopes, and aspirations. At one point, they were in almost daily discussion with one key local informant (Zhaduo) for three 
consecutive months - seeking to verify or counter, as necessary, any preconceived notion or perception that they had. They also carried out a formal questionnaire survey in two remote communities, focused on people's health status (Foggin et al. 2006). Over the years, project direction also was further refined based on outcomes of focus group discussions targeting rural health care and natural resource management practices, as well as informal meetings and numerous discussions with local colleagues and friends.

${ }^{\mathrm{h}}$ More extensive background about these community development activities can be found in (Foggin (2005a)) and (Foggin et al. (2009)).

${ }^{\mathrm{i}}$ Unfortunately, since the first draft of this article was written, educational policy in rural Qinghai Province has changed significantly, with a centralization of education focused on expanding county (and township) schools, but the closing of village schools. The lesson learned, however, remains the same: a sense of local ownership is important for long-term development success, whereas projects seen as externally driven often fail.

${ }^{j}$ This section is adapted from (Foggin et al. (2009)), which describes in more detail the authors' experience in health-related development work in the project area.

${ }^{\mathrm{k}}$ Several current examples of human-wildlife conflict in the Himalayas and Tibetan plateau region are provided by (Distefano (2005); Foggin and Rabden (2010); Lu et al. (2010); Mishra et al. (2003); Tsering (2008); Worthy and Foggin (2008)), and (Xu et al. (2008a)).

\begin{abstract}
Acknowledgements
The work described in this paper would not have been possible without the joint working, genuine help, guidance, support and encouragement of many friends and colleagues. However, we would like to extend a special word of thanks to Hashi Zhaxi Duojie, who was instrumental in the communities' mobilization and in the execution of the work. Likewise, we also wish to thank the following people for long-term their involvement and support: Bolei, Peter Foggin, Gongbu Zhaxi, Huting, Qingmei Randing, John Sale, Walter Willms, and Fiona Worthy. Plateau Perspectives' Board of Directors (Canada), Trustees (Scotland) and international Council of Reference, as well as our funding partners including HimalPartner and Ford Foundation, provided invaluable support. None of this work would have been possible without them. We also appreciate the valuable recommendations made by two anonymous reviewers, which helped us to clarify and improve the manuscript
\end{abstract}

Author details

${ }^{1}$ Plateau Perspectives, 200 Walnut Avenue, St Lambert, Quebec, J4P 2T1, Canada ${ }^{2}$ School of Geography and Life Sciences, Qinghai Normal University, 38 Wusi Xilu, Xining City, Qinghai Province, 810008, People's Republic of China

\title{
Authors' contributions
}

JMF and METF jointly designed and executed the project work described in this article. JMF drafted the manuscript, and METF critically revised the manuscript. Both authors have approved the final manuscript for publication.

\section{Authors' information}

Marc Foggin received his PhD in Biology at Arizona State University in 2000. He is also founding director of the nonprofit organization, Plateau Perspectives, which supports community development and environmental protection in the Tibetan Plateau region of China.

Marion Torrance-Foggin was consultant paediatrician in the Northumberland, UK, before coming to China and joining the Plateau Perspectives team. She is specialized in community child health.

\section{Competing interests}

The authors declare that they have no competing interests.

Received: 24 June 2011 Accepted: 20 October 2011 Published: 20 October 2011

\section{References}

Aronson, DR. 1980. Must nomads settle? Some notes toward policy on the future of pastoralism. In When Nomads Settle: Processes of Sedentarization as Adaptation and Response, ed. Salzman PC, Sadala E, 173-184. New York: J.F. Bergin Publishers.

Azarya, V. 1996. Nomads and the State of Africa: The Political Roots of Marginality. African Studies Centre Leiden. Aldershot: Avebury. 
Bacon, EE. 1966. Central Asians Under Russian Rule: A Study in Culture Change. Ithaca: Cornell University Press. Banks, T. 2003. Property Rights Reform in Rangeland China: Dilemmas On the Road to the Household Ranch. World Development 31(12): 2129-2142. doi:10.1016/j.worlddev.2003.06.010.

Banks, T, C Richard, and Z Yan. 2003. Community-based grassland management in Western China: Rationale, pilot project experience, and policy implications. Mountain Research and Development 23(2): 132-140. doi:10.1659/0276-4741(2003) 023[0132:CGMIWC]2.0.CO;2.

Bennett, JW. 1988. The political ecology and economic development of migratory pastoralist societies in Eastern Africa. In Power and Poverty: Development Projects in the Third World, ed. Attwood DW, Bruneau TC, Galaty JGS. 31-60. Westview Special Studies in Social, Political, and Economic Development. Boulder: Westview Press.

Berkes, F, and C Folke. 1998. Linking Social and Ecological Systems: Management Practices and Social Mechanisms for Building Resilience. New York: Cambridge University Press.

Blench, R. 2001. 'You can't go home again' - Pastoralism in the new millennium. London: Overseas Development Institute.

Breivik, I. 2007. The political ecology of grassland conservation in Qinghai Province, China: Discourse, policies and the herders. MA thesis, Department of International Environment and Development Studies (NORAGRIC), Norwegian University of Life Sciences. Aas, Norway.

Cardenas, JC, J Stranlund, and C Willis. 2000. Local Environmental Control and Institutional Crowding-Out. World Development 28(10): 1719-733. doi:10.1016/\$0305-750X(00)00055-3.

Chambers, R. 1983. Rural Development: Putting the Last First. London: Longman.

Chandler, MJ, and CE Lalonde. 2008. Cultural continuity as a moderator of suicide risk among Canada's First Nations. In Healing traditions: The mental health of Aboriginal peoples in Canada, ed. Kirmayer L, Valaskakis GS. 221-248. Vancouver: University of British Columbia Press.

Chandler, MJ, and CE Lalonde. 1998. Cultural continuity as a hedge against suicide in Canada's First Nations. Transcultural Psychiatry 35(2): 193-211.

Ciren, Y. 2006. The Household Responsibility Contract System and the Question of Grassland Protection: A case study from the Chang Tang, northwest TAR. MA thesis, Department of Indigenous Studies, University of Tromsø, Norway. http:// www.ub.uit.no/munin/bitstream/10037/291/1/thesis.pdf. Accessed 9 June 2011.

Comaroff, JL. 2009. Ethnicity, Inc. Chicago: University of Chicago Press.

Combe, GA. 1926. A Tibetan on Tibet. New Delhi: Aryan Books International. [Reprinted 1994.].

Cooke, B, and U Kothari. 2001. Participation: the New Tyranny? New York: Zed Books.

Cyranoski, D. 2005. The long-range forecast. Nature 438: 275-276. doi:10.1038/438275a.

Distefano, E. 2005. Human-Wildlife Conflict Worldwide: Collection of case studies, analysis of management strategies and good practices. Rome: FAO.

Du, F. 2006. Grain for Green and Poverty Alleviation: The Policy and Practice of Ecological Migration in China. Horizons 9(2): 46.

Du, F. 2009. Ecological Resettlement Policies Increase Herder Vulnerability and Poverty - Ecological Resettlement Policy and Practice in Qinghai. Presentation at conference 'Sustaining Herder Community-based Grassland Management Through Improved Government Policies and Practices' in Beijing, China, on 18 December 2009. http://cress.cass.cn/xscg/bg/ P020091223602808752792.pdf. Accessed 10 January 2011.

Du, F. 2010. Ecological Resettlement for Tibetan Herders in the Source Area of the Three Rivers of Qinghai Plateau China., [Abstract]. International Indigenous Studies Program, University of Calgary, 21 June 2010. http://arts.ucalgary.ca/events/drfachun-du. Accessed 9 June 2011.

Dyson-Hudson, N. 1985. Pastoral production systems and livestock development projects: An East African perspective. In Putting People First: Sociological Variables in Rural Development, ed. Cernea M, 157-186. Oxford: Oxford University Press.

Economy, EC. 2004. The River Runs Black: The Environmental Challenge to China's Future. Ithaca: Cornell University Press.

Ekvall, RB. 1968. Fields on the Hoof: Nexus of Tibetan Nomadic Pastoralism. New York: Holt, Rinehart and Winston.

Ekvall, RB. 1974. Tibetan nomadic pastoralists: Environments, personality, and ethos. Proceedings of the American Philosophical Society 118: 519-537.

Ellis, JE, and DM Swift. 1988. Stability of African pastoral ecosystems: Alternate paradigms and implications for development. Journal of Rangeland Management 41: 450-459. doi:10.2307/3899515.

Eriksson, M, J Xu, AB Shrestha, RA Vaidya, S Nepal, and K Sandström. 2009. The Changing Himalayas: Impact of Climate Change on the Water Resources and Livelihoods in the Greater Himalayas. Kathmandu: International Centre for Integrated Mountain Development (ICIMOD).

Fitzpatrick, JL, JR Sanders, and BR Worthen. 2004. Program Evaluation: Alternative Approaches and Practical Guidelines. Boston: Allyn and Bacon.

Foggin, JM. 2000. Biodiversity protection and the search for sustainability in Tibetan plateau grasslands. PhD dissertation, Department of Biology, Arizona State University. Tempe.

Foggin, JM. 2005a. Highland Encounters: Building new partnerships for conservation and sustainable development in the Yangtze River headwaters, heart of the Tibetan Plateau. In Innovative Communities: People-centred Approaches to Environmental Management in the Asia-Pacific Region, ed. Velasquez J, Yashiro M, Yoshimura S, wOno I, 131-157. Tokyo: United Nations University Press.

Foggin, JM. 2005b. Promoting Biodiversity Conservation and Community Development in the Sanjiangyuan Region: Proceedings of a conservation planning meeting, with agreed priority action points. Conservation planning meeting cohosted by Plateau Perspectives, Upper Yangtze Organization, Government of Zhiduo County and Sanjiangyuan National Nature Reserve Management Bureau held in Yushu, China, Sep 30 - Oct 13, 2005. Xining: Plateau Perspectives.

Foggin, JM. 2008. Depopulating the Tibetan grasslands: National policies and perspectives for the future of Tibetan herders in Qinghai Province, China. Mountain Research and Development 28(1): 26-31. doi:10.1659/mrd.0972.

Foggin, JM. 2010. ICCAs as 'contract conservation' in the Chinese Tibetan Plateau region. In Bio-cultural diversity conserved by indigenous peoples and local communities - examples and analysis. In Companion document to IUCN/CEESP Briefing Note 10: Strengthening what works - Recognising and supporting the conservation achievements of indigenous peoples and local communities, ed. Borrini-Feyerabend G, 61-62. Prepared for GEF SGP, GTZ and IUCN/CEESP by ICCA Consortium. 
Foggin, JM. 2011a. Rethinking 'ecological migration' and the value of cultural continuity: A response to Wang, Song and $\mathrm{Hu}$. AMBIO 40(1): 100-101. doi:10.1007/s13280-010-0105-5.

Foggin, JM. $2011 \mathrm{~b}$. Local Communities and Conservation on the Tibetan Plateau: Two case studies of collaborative management in the Sanjiangyuan region. Paper presented at the International Symposium on the Human Dimensions of Ecological Conservation on the Tibetan Plateau, in Xining on 21-16 August 2011. Hosted by the Qinghai Academy of Social Sciences (QASS) Xining: QASS.

Foggin, JM, and MH Bass. 2010. Mainstreaming Environment into Development: Collaborative land management in the Tibetan grasslands, China. LEAD International. http://www.lead.org/page/573. Accessed 9 July 2011.

Foggin, JM, and J Phillips. 2010. Looking for stability: Holistic policy analysis in light of rapid development among Kham Tibetan herding groups. Himalayan Journal of Development and Democracy 5(1): 64-71.

Foggin, JM, and J Phillips. Forthcoming. Horizontal Policy Analysis: A tool to promote sustainable livelihoods development; with implications for Ecological Resettlement and other major development programs in the Tibetan Plateau region. In Pastoralism in China Today, ed. Kolås Å, Zhaluo. Beijing: Social Science Academic Press.

Foggin, JM, and J Rabden. 2010. Trial use of electric fencing to prevent intrusions by Tibetan brown bear. International Bear News 19(1): 15-18.

Foggin, PM, and JM Foggin. 2008. The practice and experience of settlement and relocation among Canada's Aboriginal peoples. In In the Proceedings of the Canada-China Forum, Western Development and Socio-Economic Change, ed. Potter P, Du F, . Beijing: Institute of Ethnology and Anthropology (IEA), Chinese Academy of Social Sciences (CASS) and University of British Columbia (UBC).

Foggin, PM, ME Torrance, D Dorje, W Xuri, JM Foggin, and J Torrance. 2006. Assessment of the health status and risk factors of Kham Tibetan pastoralists in the alpine grasslands of the Tibetan Plateau. Social Sciences and Medicine 63: 2512-2532. doi:10.1016/j.socscimed.2006.06.018.

Foggin, PM, ME Torrance, and JM Foggin. 2009. Accessibility of Healthcare for Pastoralists in the Tibetan Plateau Region: A case study from southern Qinghai Province, China. In Ethnic Minorities and Regional Development in Asia: Reality and Challenges, ed. Cao Hua, 83-91. Amsterdam: Amsterdam University Press.

Freire, P. 1970. Pedagogy of the oppressed. New York: Continuum Press.

Galaty, JG, and DL Johnson. 1990. The World of Pastoralism: Herding Systems in Comparative Perspective. New York: Guilford Press.

Ghai, D, and JM Vivian. 1992. Grassroots Environmental Action: People's Participation in Sustainable Development. London: Routledge Press.

Glaser, BG, and A Strauss. 1967. Discovery of Grounded Theory: Strategies for Qualitative Research. Mill Valley, Ca: Sociology Press.

Glaser, BG. 1992. Basics of Grounded Theory Analysis: Emergence vs Forcing. Mill Valley, Ca: Sociology Press.

Goldstein, MC, and CM Beall. 1991. Change and Continuity in Nomadic Pastoralism on the Western Tibetan Plateau. Nomadic Peoples 28: 105-123.

Goldstein, MC, and CM Beall. 1990. Nomads of Western Tibet: The Survival of a Way of Life. Berkeley: University of California Press.

Hansen, HF. 2005. Choosing Evaluation Models: A Discussion on Evaluation Design. Evaluation 11(4): 447-462. doi:10.1177/ 1356389005060265.

Hao, X. 2008. A Green Fervor Sweeps the Qinghai-Tibetan Plateau. Science 321: 633-635. doi:10.1126/science.321.5889.633.

Hecht, S, and A Cockburn. 1990. The Fate of the Forest: Developers, Destroyers and Defenders of the Amazon. London: Penguin Books.

Ho, P. 1998. Ownership and control in Chinese rangeland management since Mao: A case study of the free-rider problem in pastoral areas in Ningxia. In Cooperative and Collective in China's Rural Development: Between State and Private Interests, ed. Vermeer EB, Pieke FN, Chong WL, 196-235. Armonk: M.E. Sharpe.

Hodgson, DL. 2001. Once Intrepid Warriors: Gender, Ethnicity, and the Cultural Politics of Maasai Development. Bloomington: Indiana University Press.

HPG (Humanitarian Policy Group) 2009. Social protection in pastoral areas. London: ODI http://www.odi.org.uk/resources/ download/3300.pdf. Accessed 8 September 2011.

Huber, T. 2003. The Chase and the Dharma: The legal protection of wild animals in premodern Tibet. In Wildlife in Asia: Cultural perspectives, ed. John Knight, 36-55. Man and Nature in Asia Series. New York: Routledge.

Huber, T. 2005. Antelope Hunting in Northern Tibet: Cultural Adaptations to Wildlife Behaviour. Memorie della Societa italiana di Scienze Naturali e del Museo Civico di Storia naturale di Milano 33: 5-7, [Special Issue: Wildlife and Plants in Traditional and Modern Tibet: Conceptions, Exploitation, and Conversation].

Jaireth, H, and D Smyth. 2003. Innovative Governance: Indigenous Peoples, Local Communities and Protected Areas. Published for IUCN, CEESP, WCPA and TILCEPANew Delhi: Ane Books.

Klassen, A, A Miller, N Anderson, J Shen, V Schiariti, and M O'Donnell. 2005. Performance measurement and Improvement frameworks in health, education and social services systems: a systematic review. International Journal for Quality in Health Care 22(1): 44-69.

Lalonde, CE. 2005. Counting the costs of failures of personal and cultural continuity. Human Development 46: 137-144.

Leeuwen, VC, T Emeljanenko, and L Popova. 1994. Nomads in Central Asia: Animal Husbandry and Culture in Transition (19th - 20th century). Amsterdam: Royal Tropical Institute.

Loomis, D. 1998. Desert rangeland livestock management in Soviet Central Asia. Journal of Arid Environments 17: 1-12.

Lu, J, D Hu, and L Yang. 2010. Legal status and conservation of cat species in China. CATnews - IUCN/SSC Cat Specialist Group , 5: 5-6, [Cats in China, eds C. Breitenmoser-Würsten and U. Breitenmoser].

McBeath, J, and JH McBeath. 2006. Biodiversity Conservation in China: Policies and Practice. Journal of International Wildlife Law and Policy 9: 1-25. doi:10.1080/13880290500343657.

McNiff, J. 2002. Action research for professional development. http://www.jeanmeniff.com/ar-booklet.asp. Accessed 7 September 2011.

McNiff, J, and D Whitehead. 2009. Doing and Writing Action Research. London: Sage Publications. 
Mei, J, and Y Zhang. 2004. A biodiversity conservation and community livelihood co-management plan for the Suojia area of Qinghai, China. Xining: Qinghai Environmental Protection Bureau (QEPB), Upper Yangtze Organisation (UYO) and Fauna and Flora International (FFI).

Mishra, C, P Allen, T McCarthy, M Madhusudan, A Bayarjargal, and H Prins. 2003. The role of incentive programs in conserving the Snow Leopard. Conservation Biology 17(6): 1512-1520.

Morton, K. 2008. China and Environmental Security in the Age of Consequences. Asia Pacific Review 15(2): 52-67.

Morton, K. 2007a. Civil Society and Marginalisation: Grassroots NGOs in Qinghai Province. In Marginalisation in China: Perspectives on Transition and Globalisation, ed. Zhang H, Wu B, Sanders R. 239-256. Aldershot: Ashgate Publishing.

Morton, K. 2007b. Transnational Advocacy at the Grassroots: Benefits and Risks of International Cooperation. In China's Embedded Activism: Opportunities and Constraints of a Social Movement, ed. Ho P, Edmonds RL, 195-215. New York: Routledge Press.

Norbu, N, and N Simmons. 1997. Journey among the Tibetan Nomads: An Account of a Remote Civilization. Library of Tibetan Works and Archives (LTWA).

Phillips, J. 2009. Developing Kham: A Way Forward. Presentation at the Fourth Annual Himalayan Policy Research Conference at Madison, 22 October 2009 Organized by the Nepal Study Center, University of New Mexico.

Polycarpou, L. 2010. The Glaciers Disappear: The Startling Photos of David Breashears. State of the Planet (Earth Institute, Columbia University) http://blogs.ei.columbia.edu/2010/07/19/the-glaciers-disappear-the-startling-photos-of-davidbreashears/. Accessed 11 January 2011.

Pretty, J. 2005. The many interpretations of participation. In Focus 16: 4-5.

Richard, C, Z Yan, and G Du. 2006. The paradox of the individual household responsibility system in the grasslands of the Tibetan Plateau, China. In Rangelands of Central Asia: Proceedings of the Conference on Transformations, Issues, and Future Challenges, ed. Bedunah DJ, McArthur ED, Fernandez-Gimenez M, 83-91. Fort Collins, Colorado: Rocky Mountain Research Station.

Salzman, PC, and E Sadala. 1980. When Nomads Settle: Processes of Sedentarization as Adaptation and Response. New York: J.F. Bergin Publishers.

Schech, S, and J Haggis. 2000. Culture and Development: A critical introduction. Oxford: Blackwell.

Schneider, HK. 1981. The pastoralist development problem. In Change and Development in Nomadic and Pastoral Societies, ed. Galaty JG, Salzman PC, 27-32. Leiden: Brill and Co.

Shao, Y, W Bleisch, and D Mallon. 2006. Community participation in planning and action for conservation on the QinghaiTibet Plateau. In Conservation Biology in Asia,ed. McNeely JA, McCarthy ATM, Smith L, . Olsvig-Whittaker and E.D. Wikramanayake, 115-127. Kathmandu, Nepal: Society for Conservation Biology (Asia Section) and Resources Himalaya.

Spooner, B. 1973. The cultural ecology of pastoral nomads. Current Topics in Anthropology: Theory, Methods, and Content 8: $1-53$.

Stevens, S. 1973. Conservation through cultural survival: indigenous peoples and protected areas. Island Press: Washington, D.C.

Swift, J, C Toulmin, and S Chatting. 1990. Providing Services for Nomadic People: A review of the literature and annotated bibliography. UNICEF Staff Working Papers No. 8. UNICEF: New York.

Taylor, J. 1971. Negotiating the Grassland: The policy of pasture enclosures and contested resource use in Inner Mongolia. Human Organization 65(4): 374-386.

Taylor-Ide, D, and CE Taylor. 2002. Just and Lasting Change: When Communities Own Their Futures. Baltimore and London: The John Hopkins University Press, in association with Future Generations.

Tignor, RL. 1971. Kamba Political Protest The Destocking Controversy of 1938. African Historical Studies 4(2): 237-251.

Tignor, RL. 1976. The Colonial Transformation of Kenya: The Kamba Kikuyu, and Maasai from 1900 to 1939. Princeton: Princeton University Press.

Tserendash, S, and B Erdenebaatar. 1993. Performance and management of natural pasture in Mongolia. Nomadic Peoples 33: 9-15.

Tsering, D. 2008. Human-Brown Bear Conflict Reduction in the Chang Tang Region of Tibet. International Bear News 17(3): 9-12.

UNEP/GRID-Arendal. 2007. Water towers of Asia-glaciers, water and population in the greater Himalayas-Hindu Kush-Tien Shan-Tibet region. UNEP/GRID-Arendal Maps and Graphics Library. http://maps.grida.no/go/graphic/water-towers-of-asiaglaciers-water-and-population-in-the-greater-himalayas-hindu-kush-tien-shan-tib. Accessed 14 January 2011.

Velasquez, J, M Yashiro, S Yoshimura, and I Ono. 2005. Innovative Communities: People-centred Approaches to Environmental Management in the Asia-Pacific Region. Tokyo: United Nations University Press.

Vermeer, EB, FN Pieke, and WL Chong. 1998. Cooperative and Collective in China's Rural Development: Between State and Private Interests. Armonk: M.E. Sharpe.

Vollan, B. 2010. Socio-ecological explanations for crowding-out effects from economic field experiments in southern Africa. Ecological Economics 67: 560-573.

Wang, Z, K Song, and L Hu. 2010. China's largest scale ecological migration in the three-river headwater region. AMBIO 39(56): 443-446.

Wang, Z, K Song, and L Hu. 2011. Response to 'rethinking ecological migration and the value of cultural continuity'. AMBIO 40(1): 102-103.

Westing, AH. 2005. Core values for sustainable development. Environmental Conservation 23: 218-225.

Williams, DM. 2002. Beyond Great Walls: Environment, Identity, and Development on the Chinese Grasslands of Inner Mongolia. Palo Alto: Stanford University Press.

Worthy, FR, and JM Foggin. 2008. Conflicts between local villagers and Tibetan brown bears (Ursus arctos) threaten conservation of bears in a remote region of the Tibetan plateau. Journal of Human-Wildlife Conflicts 2(2): 200-205.

Xu, A, Z Jiang, C Li, J Guo, S Da, Q Cui, S Yu, and G Wu. 2008a. Status and conservation of the snow leopard Panthera uncia in the Gouli Region, Kunlun Mountains, China. Oryx 42(3): 460-463.

Xu, B, J Cao, J Hansen, T Yao, DR Joswia, N Wang, G Wu, M Wang, H Zhao, W Yang, X Liu, and J He. 2009. Black Soot and the Survival of Tibetan Glaciers. Proceedings of the National Academy of Sciences of the USA 106(52): 22114-22118. 
Xu, JC, Y Yang, Z Li, N Tashi, R Sharma, and J Fang. 2008b. Understanding Land Use, Livelihoods, and Health Transitions among Tibetan Nomads: A Case from Gangga Township, Dingri County, Tibetan Autonomous Region of China. EcoHealth 5(2): 104-114. doi:10.1007/s10393-008-0173-1.

Yeh, E. 2000. Forest Claims, Conflicts and Commodification: The Political Ecology of Tibetan Mushroom-Harvesting Villages in Yunnan Province, China. The China Quarterly 161: 264-278.

Zhao, M. 2009. Tibetan plateau in peril. Far Eastern Economic Review (online). http://www.feer.com/international-relations/ 20098/january58/Tibetan-Plateau-in-Peril. Accessed 24 May 2009.

doi:10.1186/2041-7136-1-21

Cite this article as: Foggin and Torrance-Foggin: How can social and environmental services be provided for mobile Tibetan herders? Collaborative examples from Qinghai Province, China. Pastoralism: Research, Policy and Practice 2011 $1: 21$

\section{Submit your manuscript to a SpringerOpen ${ }^{\circ}$} journal and benefit from:

- Convenient online submission

- Rigorous peer review

- Immediate publication on acceptance

- Open access: articles freely available online

- High visibility within the field

- Retaining the copyright to your article

Submit your next manuscript at $\boldsymbol{s p r i n g e r o p e n . c o m ~}$ 